\title{
A Measure of Nature Connectedness for Children and Adults: Validation, Performance, and Insights
}

\author{
Miles Richardson ${ }^{1, *}{ }^{\mathbb{D}}$, Anne Hunt ${ }^{2}$, Joe Hinds ${ }^{3}$, Rachel Bragg ${ }^{4}$, Dean Fido ${ }^{1} \mathbb{1}$, \\ Dominic Petronzi ${ }^{1}$, Lea Barbett ${ }^{1}$ (D), Theodore Clitherow ${ }^{5}$ and Matthew White ${ }^{5}$ \\ 1 Human Sciences Research Centre, University of Derby, Derby DE22 1GB, UK; D.Fido@derby.ac.uk (D.F.); \\ D.Petronzi@derby.ac.uk (D.P.); L.Barbett@derby.ac.uk (L.B.) \\ 2 Valuing Environment Team, Natural England, York YO1 7PX, UK; anne@naturalsolutions.org.uk \\ 3 Department of Psychology, Social Work and Counselling, Faculty of Education \& Health, \\ University of Greenwich, Greenwich, London SE10 9LS, UK; J.Hinds@greenwich.ac.uk \\ 4 Care Farming UK, Bristol BS3 4NA, UK; rachel@farmgarden.org.uk \\ 5 European Centre for Environment and Human Health, University of Exeter Medical School, Truro, \\ Cornwall, TR1 3HD, UK; tc446@exeter.ac.uk (T.C.); Mathew.White@exeter.ac.uk (M.W.) \\ * Correspondence: m.richardson@derby.ac.uk
}

Received: 28 March 2019; Accepted: 20 May 2019; Published: 12 June 2019

\begin{abstract}
With benefits to both human well-being and pro-nature conservation behaviors, nature connectedness is emerging as an important psychological construct for a sustainable future. The growing research and applied and policy-related interests require a straightforward measure of nature connectedness that is suitable for both children and adult populations. To establish the reliability of the new Nature Connection Index (NCI) three factor analyses were conducted. One was based on a large Monitor of Engagement with the Natural Environment (MENE) dataset for adults $(n=3568)$ with a replication from data sets collected online $(n=553)$, and a third used MENE data from children $(n=351)$. To validate the $\mathrm{NCI}$ as a measure for nature connectedness an online comparison study $(n=153)$ included the NCI alongside other established measures. The results showed that the NCI was a reliable and valid scale that offers a short, simple alternative to other measures of nature connectedness, particularly for populations including both children and adults, measured face to face or online. The utility of the $\mathrm{NCI}$ is also supported, with variations associated with various pro-environmental and pro-conservation behaviors observed, and importantly the NCI also revealed changes in nature connectedness across the lifespan.
\end{abstract}

Keywords: nature connectedness; pro-nature conservation behaviors; lifespan

\section{Introduction}

Human connection with the rest of nature is a topic of increasing research interest [1] and is being recognized as of relevance to government policy relating to both human health and well-being and the natural environment [2]. This focus is required owing to the crises in mental well-being [3] and in planetary health owing to the effects of climate change from human activities [4]. A growing body of evidence suggests that nature connectedness has benefits to mental well-being (for reviews see $[5,6]$ ) and can also help deliver pro-environmental attitudes and behaviors [7-9]. The negative human impact on planetary health suggests a failing relationship between people and the rest of nature. There is a need for a renewed sustainable relationship, one that benefits the natural world, but can also benefit human well-being. Given the apparent benefits to well-being and influence on pro-nature behaviors, nature connectedness is emerging as an important construct that can help develop a more sustainable relationship with the natural world. Importantly, nature connectedness is defined, can be measured and increased through large-scale campaigns [10]. 
With the need for a new human relationship with nature and growing interest in a policy context [2], population measures of nature connectedness are needed to complement those that are already being used to help monitor and report on people's relationship with nature, for example the range of natural environment attitude and behavior measures captured through the Monitor of Engagement with the Natural Environment Survey (MENE). Such measures are used to help target, design, and evaluate strategic policy and practice interventions. Although a range of measures for nature connectedness have been developed [11], none of these measures would be suitable for use in a national survey context due to the number, length, and complexity of item wording. Nor are these measures suitable for use with both adults and children, which would be necessary to allow patterns across the lifespan to be monitored and offer the potential for longitudinal research. To meet an emerging need for population level data on nature connectedness, a collaboration of partners recently funded the development and testing of a short, simple measure suitable for use with both children and adults. The new measure, the Nature Connection Index (NCI), was developed and tested through use in the existing omnibus survey the MENE survey, which has accredited National Statistic status in the UK.

This paper provides background information on the new measure, presents the strengths and limitations of this as an approach and provides insight into what the new index reveals about nature connectedness in both children and adults.

\subsection{Summary of the Rationale for Developing a New Measure for Nature Connectedness}

The construct of connectedness to nature has multiple dimensions, including affective, cognitive and experiential factors related to our belonging to the natural world [12,13]. Nature connectedness is also concerned with an individual's sense of self [14], where nature and humanity are one. Given the multiple factors, there are several measures used for adult populations (see [11] for a review) and those for children e.g., [15]. Each measure approaches the construct from a slightly different perspective, with some debate regarding how measures might tap into beliefs people hold about their connection to nature, rather than an individual's affective relationship [16]. However, all were found to measure the construct of nature connectedness [11].

There is also interest in the relationship between childhood and adult nature connectedness and how it varies across the lifespan. Concern is often expressed about children's lack of connection with nature [17] and research has shown that the level of nature connectedness is below that associated with pro-conservation behaviors [18]. However, there is little data on the profile of nature connectedness across the lifespan. The NCI is intended to allow such data to be collected and through monitoring trends reveal factors linked to disconnection in childhood. Childhood and adolescence is a time of many significant physical and psychological changes where children develop an identity, form social relationships, competences, and goals that may conflict with a close connection with nature.

A measure suitable for gathering population data across the lifespan needs to be simple and short. Many of the existing scales and their items are too long and complex and not suitable for use in a national survey context. A current successful short scale, the NR-6, provides an excellent tool for research, but the items are less suitable for children, and perhaps a little esoteric even for some sections of the adult population, e.g., "My connection to nature and the environment is a part of my spirituality". While the child-focused Connection to Nature Index (CNI) is straightforward to understand [15] and has demonstrated some diagnostic utility with regard to conservation behaviors [18], it is long, and some items are not that suitable for the wider adult population.

\subsection{Summary of the Approach}

An affective connection plays an important role in people's engagement with the natural environment [19] and is emerging as a potential mechanism for the well-being benefits [20]. Therefore, affect was a key factor informing the development of the new measure. Item selection considered people's affective and experiential relationship with nature, rather than a focus on cognitive appraisals about nature. A framework to inform the item themes within the NCI was provided by the pathways 
to nature connectedness: emotion, beauty, contact, meaning and compassion [21]. These five types of relationship with nature have been found to explain a high level of variance in nature connectedness [21]. The pathways themselves are a subset of the nine values of biophilia (utilitarian, naturalistic, ecologistic-scientific, aesthetic, symbolic, humanistic, moralistic, dominionistic, negativistic) [22]. Further guidance was provided by reviews of existing nature connection measures e.g., $[23,24]$.

\subsection{Justification for the NCI Items}

1. The first item related to the nature connectedness pathways [21] is emotion, "Being in nature makes me very happy". An emotional attachment to nature is essential to nature connectedness [12], and is captured in the humanistic value of biophilia. Happiness has an affective component, it is an emotional experience linked to improvements in nature connectedness and well-being $[5,13]$. Existing measures of nature connection include happiness, e.g., "Being outdoors makes me happy" [15].

2. Given the first item is also a well-being benefit, a second item on emotion takes a different emotional pathway perspective, "I find being in nature really amazing". States such as amazement, awe and wonder have been associated with eudemonic aspects of experience and therefore are differentiable from happiness [25]. Nature is known to be associated with positive feelings, such as awe and wonder [26,27] and wonder is often noted in observations of everyday nature [28]. Again, such emotional responses are associated with enhancing nature connectedness [29,30].

3. The third item is related to the beauty pathway [21], "I always find beauty in nature". People are known to prefer aesthetically pleasing nature [31]. More recently, engagement with natural beauty has been shown to be involved in the relationship between nature connectedness and well-being $[20,32,33]$.

4. The fourth item is related to the contact and meaning pathways [21], "Spending time in nature is very important to me". Research into nature connectedness has placed an emphasis on direct experiences with nature that foster an affective relationship [19,34]. Such experiences of nature require time in it and time in nature can promote increased levels of nature connectedness [35-37]. It is an aspect included in other measures, for example "Spending time in nature is important to $\mathrm{me}^{\prime \prime}$ is included in the Environmental Identity Scale [38].

5. The fifth item is related to the compassion pathway [21], "I always treat nature with respect". The compassion pathway is derived from the moralistic value of biophilia which involves ethical judgements and revering nature. In framing this aspect suitably for children, the decision was taken to use the term "respect". Reverence is related to respect and respectful actions towards nature involve ethical judgements. The item has a behavioral focus as there can be a gap between values and action [39]. Furthermore, an action-based framing for this pathway was found to be an important indicator of nature connectedness, slightly above a value framing [21]. Nature connectedness is linked to pro-environmental attitudes [12,40], and behaviors [13]. This conservation of nature is captured within the moralistic value of biophilia $[21,22,41]$. This aspect of nature connectedness is found in existing measures, e.g., the Nature Relatedness Scale for adults [42].

6. The sixth item "I feel part of nature" reflects that connectedness to nature encompasses both affective and experiential sense of belonging to the natural world [12]. It relates to a person's understanding of their interconnectedness with nature and their sense of inclusion within nature. It also reflects that nature connectedness captures a breadth of concepts including inclusion of self in nature, cognitive appraisals, appreciation of nature and emotional affiliations e.g., [43]. Feeling part of nature is an overarching aspect that taps directly into the concept of humans having a shared place within the natural world. It is a concept included in several other measures of nature connection, often less directly, and the sole concept of the single-item Inclusion of Nature in Self scale [44]. 


\subsection{Summary of Methodology for Development of the NCI}

Full details of the development work are detailed in [45]. Participants in the development were collected from early phases of the MENE data collected 2015/16 $(n=1294)$. Key aspects included adopting a 7-point response scale, "completely agree" to "completely disagree" based on data from the pilot sample. This was preferred to a 5-point "strongly agree/disagree" as it provided a greater spread of scores. Results from the pilot, for example skewness, also led to the development of a weighted points index from zero to a maximum score of 100 in line with expectations for a national indicator approach and following standard approaches to data transformation [46]. The points index was scaled using the relative weight of item responses based on the distribution of the sum of inverse scores and variance (see column 3 of Table 1). This sum figure reflected the "importance" or "usefulness" of each item, by giving a higher value to those variables where the mean is lower. This process also gave greater weight to items with more variance to produce better discriminatory power. The sum of inverse scores and variance for the six items was then used to calculate the contribution weight (see column 4 in Table 1). These weights were then used to create the points index and value of the top answer code for each item. A non-linear power function was then used to scale the remaining six response options so that each ran from zero up to the maximum. A non-linear approach was taken to give greater emphasis to the top answer codes. The non-linear points system by item shown in Table 2 improved dispersion, producing more even percentiles with the overall impact allowing the index to better rank respondents on strength of evidence of nature connectedness. The weighted points index provided a greater spread of scores, evened out the distribution to provide differentiation in the middle range and increased the weight of the final overarching item. This ensured balanced representation of all six items and wider variation among the responses. The points index weighting was tested against unweighted scores and the simple weighting and produced the most evenly distributed index allowing the potential for categorization and banding without compromising relationships between the index and other variables of interest (e.g., ecological concern, well-being etc.). The data included both children and adults. Further development work included use of the NCI in initial large cohort studies evaluating applied interventions. Here the NCI has shown that it is sensitive to increases in nature connectedness brought about by applied interventions to engage people with nature [10].

Table 1. Calculation of weighted points index for each item.

\begin{tabular}{lcccc}
\hline & Inverse Mean & Variance & Sum & Weight (\%) \\
\hline I always find beauty in nature & 1.16 & 1.81 & 2.97 & $15.0 \%$ \\
I always treat nature with respect & 0.80 & 1.26 & 2.06 & $10.4 \%$ \\
Being in nature makes me very happy & 1.23 & 1.83 & 3.06 & $15.5 \%$ \\
Spending time in nature is very & 1.45 & 2.30 & 3.75 & $19.0 \%$ \\
important to me & 1.38 & 1.98 & 3.36 & $17.0 \%$ \\
I find being in nature really amazing & 1.93 & 2.61 & 4.54 & $23.0 \%$ \\
I feel part of nature & & & \\
\hline
\end{tabular}

Table 2. NCI items and weighted points index for each point on the response scale.

\begin{tabular}{|c|c|c|c|c|c|c|c|}
\hline \multirow[b]{2}{*}{ Statement } & \multicolumn{7}{|c|}{ Response Scale Rating } \\
\hline & 1 & 2 & 3 & 4 & 5 & 6 & 7 \\
\hline 1-I always find beauty in nature & 0 & 1 & 2 & 3 & 5 & 9 & 15 \\
\hline 2-I always treat nature with respect & 0 & 0 & 1 & 2 & 4 & 6 & 10 \\
\hline $\begin{array}{l}\text { 3-Being in nature makes me very } \\
\text { happy }\end{array}$ & 0 & 1 & 2 & 3 & 6 & 10 & 16 \\
\hline $\begin{array}{l}4 \text {-Spending time in nature is very } \\
\text { important to me }\end{array}$ & 0 & 1 & 2 & 3 & 6 & 11 & 19 \\
\hline 5-I find being in nature really amazing & 0 & 1 & 2 & 3 & 6 & 10 & 17 \\
\hline 6-I feel part of nature & 0 & 1 & 2 & 4 & 7 & 13 & 23 \\
\hline
\end{tabular}


The NCI was initially tested and developed through use in the MENE survey. As the MENE survey includes questions on environmental attitudes and behaviors there was an opportunity to look for evidence of any simple relationships between these factors (and demographics) and the NCI.

\subsection{Summary of Potential Utility of the NCI}

The potential utility of the measure lies, for example, in helping to explore key issues such as the "environmental value-action" gap which describes the disparity between the concerns people express about the natural environment and their own lifestyle. People often report strong concerns about the environment but show low commitment to changing their own behavior and engaging in pro-environmental behaviors [39]. Nature connectedness is inherently a measure of value placed on the natural environment and can be compared to both attitudinal and behavioral measures.

Furthermore, as a relatively new psychological construct, nature connectedness provides a new direction for the study of such issues. For example, early models assumed people's behavior to be rational, and proposed a linear relationship, with knowledge shaping attitudes and therefore influencing behavior [47]. However, even though environmental knowledge shows little effect on environmental behavior, it is still considered a necessary pre-requisite [48]. Newer approaches often focus on emotional factors, such as connectedness to nature. In fact, connectedness to nature may be an influential variable. It has been shown to be a much stronger predictor of environmental behavior than other factors, including knowledge [8]. As it is designed for children and adults, the NCI might be particularly useful to examine the relationship between values and behavior as the influence of connectedness to nature has been observed at several life stages [8].

To establish the validity and reliability of the NCI, the present paper reports three factor analyses. One based on a large MENE dataset for adults with a replication from data sets collected online and a third uses MENE data from children. The paper also reports variation in NCI by demographics, across the lifespan and the relationship to key attitudes and behaviors. Finally, scale characteristics resulting from producing a simple scale allow observations related to the value-action gap.

\section{Materials and Methods}

\subsection{Design and Participants}

Cross-sectional data from several sources was used. Participation in the survey was voluntary and the data collection conforms to the provisions of the Declaration of Helsinki in 1995 (and subsequent revisions). Ethical guidelines were followed as required for conducting human research.

Adult sample from the MENE survey (Factor Analysis 1): The MENE survey is part of the UK's national statistics and uses the robust protocols required when collecting data to inform policy. The MENE survey involves weekly waves of interviewing across England to reduce potential seasonal and geographical biases. In each wave, interviews are undertaken with a representative sample of the English adult population (aged 16 and over) with a sample of at least 800 achieved per wave. Data is collected in-home using Computer Assisted Personal Interviewing as part of the omnibus survey. Given the scale and coverage of MENE, the survey provided an ideal vehicle to pilot the new nature connection index. MENE is funded by the UK government's advisory body for the natural environment, Natural England with support from the government department responsible for forests and woodlands, the Forestry Commission and the UK government's Department for Environment Food and Rural Affairs. The MENE data included in the present research was collected from adults 2017/ 2018. Complete NCI responses were received from 3568 adults aged 16 to 95 years. The mean age was 49.98 years $(\mathrm{SD}=20.05)$. There were 1826 female respondents and 1742 male respondents.

Adult samples from online surveys (Factor Analysis 2): For the purposes of the second factor analysis, $\mathrm{NCI}$ data was combined from two online surveys. The first online survey was distributed via Qualtrics to 400 English adults via an online survey platform (Survey Sampling International) which pays respondents for completing surveys. The second online comparison survey was also distributed via 
Qualtrics and recruited 153 adults using opportunity sampling after participants followed a link to an online consent page and debrief. This study included existing measures for comparison. The overall profile of the 553 participants who provided the second data set collected online was 267 males and 286 females, 73 aged 18-24 years; 137 aged 25-34 years; 114 aged 35-44 years; 101 aged 45-54 years; 63 aged 55-64 years; 50 aged 65-74 years; 12 aged 74-85 and 3 aged over 85 years.

Child sample from the MENE survey (Factor Analysis 3): Participating children are selected by asking adults for permission to include children in their household in the survey (and the consent of children themselves is also required). A sample of 351 children aged 7 to 15 years with 177 female respondents and 174 males.

\subsection{Existing Measures Comparison}

To validate the $\mathrm{NCI}$ as a measure for nature connectedness, the online comparison study included the NCI alongside other established measures. (It was not possible to include these other measures in the MENE survey for the NCI development work due to the number, length, and complexity of these scales or their items.) The measures in the comparison study included:

- The single-item Inclusion of Nature in Self (INS) scale [44]. The INS represents "nature" and "self" within two circles with participants selecting the level of overlap that describes their interconnection with the natural environment.

- The six-item short-form Nature Relatedness Scale (NR-6; [49]) which comprises items that are scored on a 5-point Likert scale (where $1=$ strongly disagree, $2=$ disagree, $3=$ neutral, $4=$ agree, $5=$ strongly agree). Example items include: "I always think about how my actions affect the environment", and "My relationship to nature is an important part of who I am".

- The four-item natural beauty sub-scale from the Engagement with Beauty scale (EWNB) developed by [50] was used. The four items are: "When perceiving beauty in nature I feel something like a spiritual experience, perhaps a sense of oneness, or being united with the universe, or a love of the entire world"; "I notice beauty in one or more aspects of nature"; "When perceiving beauty in nature I feel emotional, it 'moves me,' such as feeling a sense of awe, or wonder or excitement or admiration or upliftment"; "When perceiving beauty in nature I feel changes in my body, such as a lump in my throat, an expansion in my chest, faster heartbeat, or other bodily responses". Participants responded on a 7-item "very unlike me" to "very much like me" scale.

To further explore the utility of the NCI in comparison to existing nature connectedness scales, two further measures of interest were included in the online comparison study:

- $\quad$ The 16-item Difficulties in Emotion Regulation Scale (DERS; [51]) was used to indicate ease of affect regulation. It has been found that affect regulation mediates the relationship between nature connectedness and well-being providing, an indication of alternative mechanisms and confirming the importance of affect [20]. Therefore, it is interesting to look at the relationship between affect regulation and nature connectedness. DERS has also been found to be associated with measures relevant to the benefits of nature connectedness (e.g., psychophysiological measures such as heart rate variability and generalized anxiety disorder) [52].

- A single question on happiness with an 11-point response scale, "In general, do you feel happy?" This single item offers a valid and reliable measure of well-being for community surveys and has been shown to correlate highly with multi-item well-being scales (e.g., Oxford Happiness Index and Satisfaction with Life Scale) [53]. It was included as happiness is a key well-being outcome associated with nature connectedness $[6,54]$.

As covered in the introduction and detailed in [45], the raw NCI data was adjusted through application of the points index shown in Table 2. 


\section{Results}

3.1. Summary of Results from the MENE Survey to Show NCI Variations by Gender, Age, Ethnicity, and Employment Status

The mean NCI score in adults (16 years old and over) was $61.16(\mathrm{SD}=27.88)$ and the distribution is shown in Figure 1. Females scored significantly $(p<0.01)$ higher $(64.21, \mathrm{SD}=27.36)$ than males $(57.96, \mathrm{SD}=28.08)$. The mean NCI for the non-Black, Asian and Minority Ethnic (BAME) population was $60.60(\mathrm{SD}=27.81 ; n=2761)$ and $63.06(\mathrm{SD}=28.06 ; n=807)$ for the BAME population. There were notable differences between age groups as shown in Figure 2 and Table 3. Tables 4 and 5 show the NCI by employment status and socio-economic group. Table 4 reveals a notably lower NCI for those in education; however, this group had a mean age of 21. Table 5 shows little difference between socio-economic groups. The mean score for children aged under 16 years of age was $57.45(\mathrm{SD}=25.43)$, with boys $(54.60, \mathrm{SD}=24.76)$ scoring significantly $(p=0.037)$ lower than girls $(60.25, \mathrm{SD}=25.83)$.

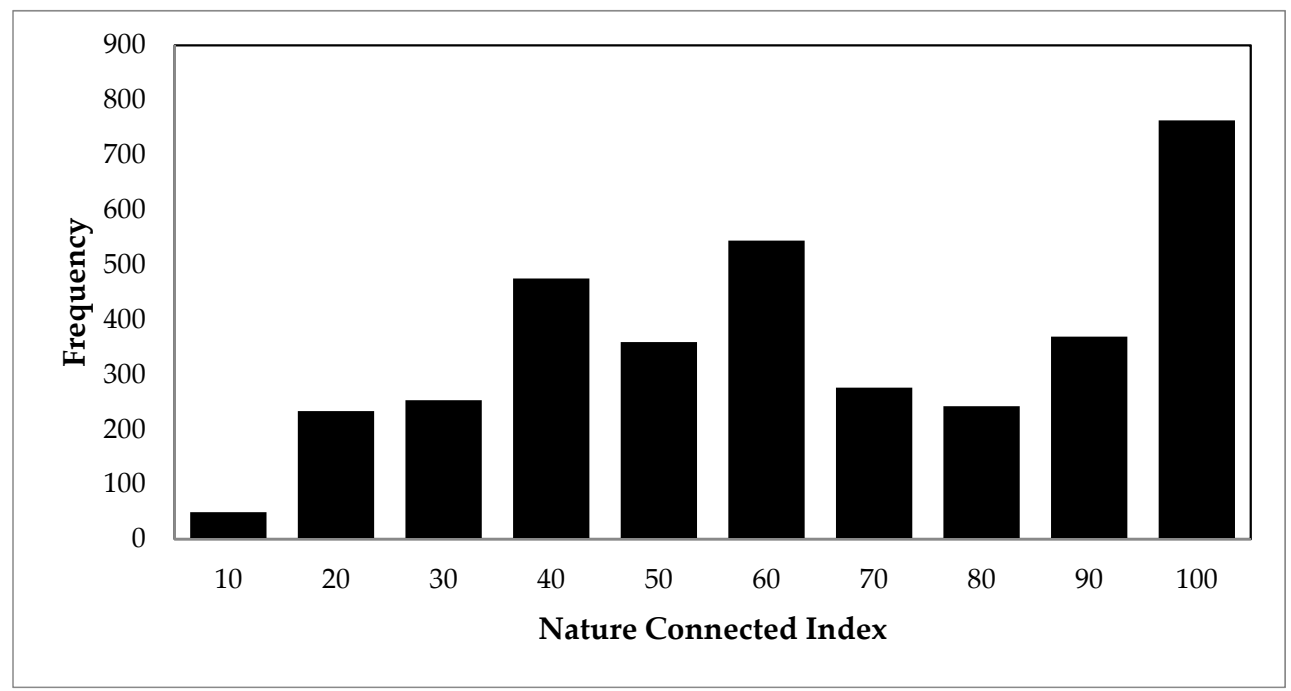

Figure 1. Distribution of adult NCI scores, $n=3568$ (Data from MENE survey).

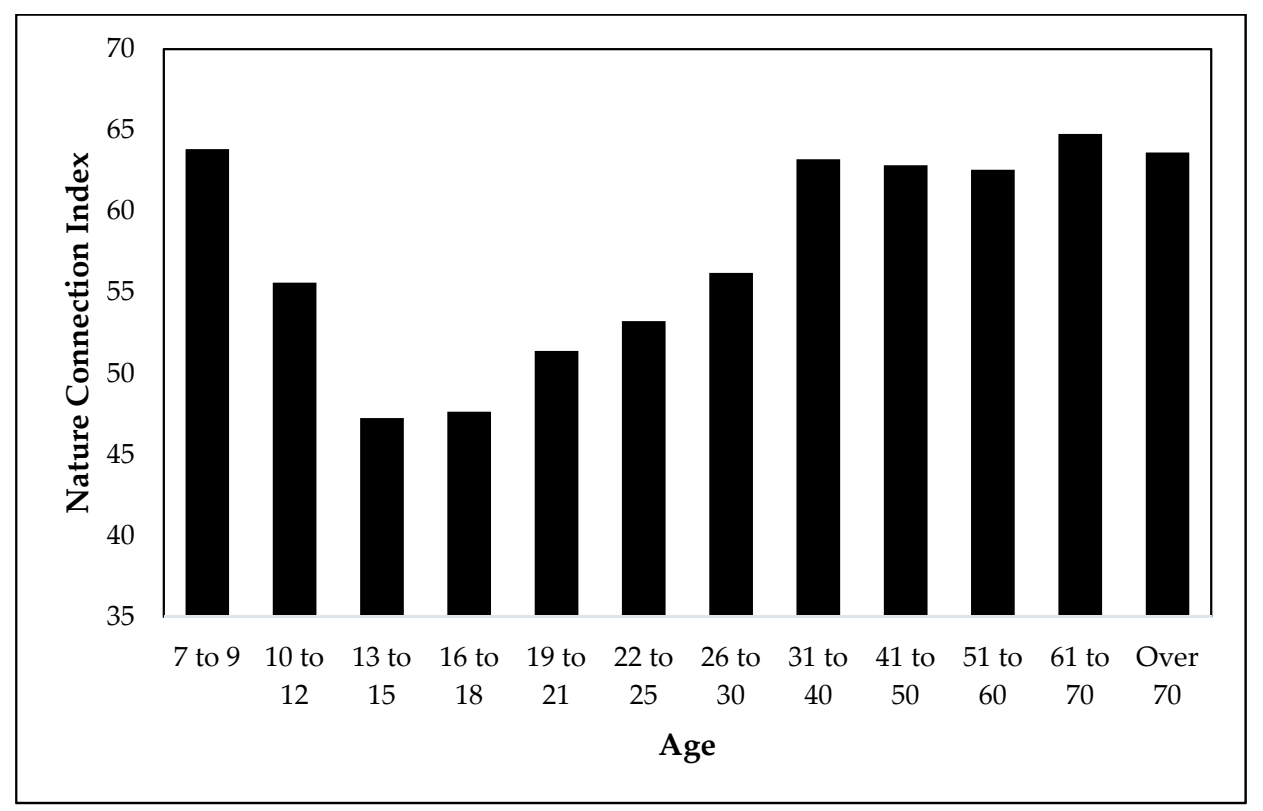

Figure 2. Mean NCI scores across the lifespan, $n=3919$ (Data from MENE survey). 
Table 3. Mean NCI scores by age (Data from MENE survey).

\begin{tabular}{|c|c|c|c|c|c|c|c|c|c|c|c|c|}
\hline Age & 7 to 9 & $\begin{array}{c}10 \text { to } \\
12\end{array}$ & $\begin{array}{c}13 \text { to } \\
15\end{array}$ & $\begin{array}{c}16 \text { to } \\
18\end{array}$ & $\begin{array}{c}19 \text { to } \\
21\end{array}$ & $\begin{array}{c}22 \text { to } \\
25\end{array}$ & $\begin{array}{c}26 \text { to } \\
30\end{array}$ & $\begin{array}{c}31 \text { to } \\
40\end{array}$ & $\begin{array}{c}41 \text { to } \\
50\end{array}$ & $\begin{array}{c}51 \text { to } \\
60\end{array}$ & $\begin{array}{c}61 \text { to } \\
70\end{array}$ & $\begin{array}{c}\text { Over } \\
70\end{array}$ \\
\hline $\mathrm{N}$ & 159 & 113 & 79 & 86 & 184 & 246 & 278 & 563 & 516 & 495 & 542 & 658 \\
\hline Mean & 63.83 & 55.60 & 47.25 & 47.64 & 51.39 & 53.23 & 56.20 & 63.21 & 62.84 & 62.56 & 64.77 & 63.62 \\
\hline SD & 24.29 & 24.08 & 26.09 & 24.82 & 24.15 & 25.52 & 27.42 & 27.27 & 28.29 & 28.22 & 28.06 & 28.27 \\
\hline
\end{tabular}

Table 4. NCI by employment status (adults only—data from MENE survey).

\begin{tabular}{lccccc}
\hline & Full Time & In Education & Not Working & Part Time & Retired \\
\hline Mean & 59.97 & 49.12 & 61.04 & 62.64 & 64.37 \\
SD & 27.67 & 23.65 & 29.22 & 26.79 & 28.00 \\
N & 1218 & 228 & 538 & 480 & 1104 \\
\hline
\end{tabular}

Table 5. NCI by socio-economic group (adults only—data from MENE survey).

\begin{tabular}{lcccc}
\hline & AB & C1 & C2 & DE \\
\hline Mean & 63.92 & 60.08 & 60.06 & 61.21 \\
SD & 26.76 & 27.29 & 27.63 & 28.95 \\
$\mathrm{~N}$ & 635 & 957 & 717 & 1259 \\
\hline
\end{tabular}

\subsection{Factor Analysis 1-Internal Consistency and Reliability (MENE Adult Data)}

Owing to both the overlapping time periods to which the data were collected as well as the conceptually different group demographics reported here (i.e., adults vs. children), we opted to report three separate Exploratory Factor Analyses (EFA) instead of conducting a follow-up confirmatory factor analysis (CFA) on a further, more-comparable sample. This approach of multiple EFAs rather than CFA is supported by work elsewhere [55]. An EFA on the 6 items of the NCI was conducted on the MENE adult cohort $(n=3568)$ using Principal Component Analysis (PCA) and varimax rotation. Bartlett's test of sphericity was significant $(p<0.001)$, indicating that factor analysis was possible, and the Kaiser-Meyer-Olkin measure (KMO) was sufficiently high (0.913), indicating sampling adequacy. The results suggested extraction of a single factor (see Figure 3), which accounted for $72.26 \%$ of the variance. Each of the 6 items had a loading threshold of more than 0.50, and together, had high internal consistency $(\alpha=0.92)$. The single factor was labelled Nature Connectedness.

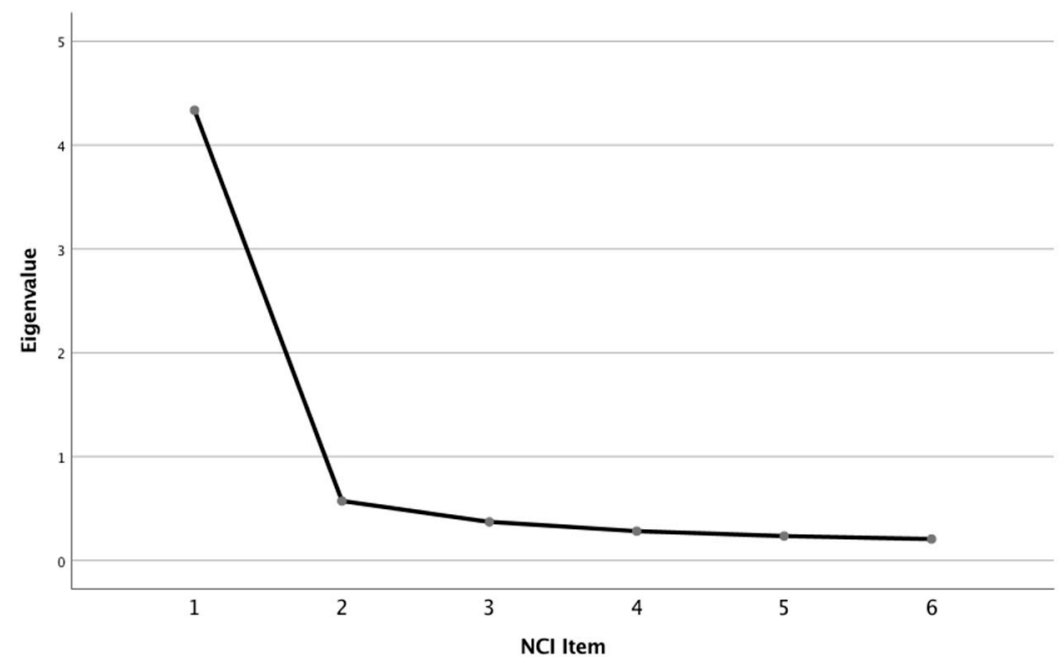

Figure 3. Factor analysis scree plot suggesting a single factor on adult cohort $(n=3568)$. 


\subsection{Scale Validity_Factor Analysis 2 (Online Data) and Factor Analysis 3 (MENE Child Data)}

Therefore, two further EFAs were conducted on NCI data from combined adult samples collected online ( $n=553)$ and a child cohort ( $n=351$; aged 7 to 15 years). Both EFAs used PCA and varimax rotation. Similar to the initial sample, Bartlett's test of sphericity was significant $(p<0.001)$ and the KMO measure was high ( 0.902 for adults, 0.871 for children). Again, a single factor solution was identified, which accounted for $68.37 \%$ and $58.18 \%$ of the variance in adults and children, respectively, with a loading threshold of more than 0.50 . This loading threshold is adequate for a sample of around 100 [56]. Together, these 6 items had high internal consistency ( $\alpha=0.92$ for adults, $\alpha=0.85$ for children). Factor loadings for each item across each sample are reported in Table 6. Given the dip in NCI observed from age 10-12 years the EFA was repeated for children aged below 11 years of age $(n=203)$ and for children aged over 10 years of age $(n=148)$. The results were similar so are not reported. Similarly, no notable differences were noted between genders.

Table 6. Factor loadings of the 6-item NCI (>.50 threshold) for adult and child cohorts.

\begin{tabular}{lccc}
\hline \multicolumn{1}{c}{ Item } & $\begin{array}{c}\text { Factor Loadings } \\
\text { (Adult } \boldsymbol{n}=\mathbf{3 5 6 8 )}\end{array}$ & $\begin{array}{c}\text { Factor Loadings } \\
\text { (Adult } \boldsymbol{n = 5 5 3 )}\end{array}$ & $\begin{array}{c}\text { Factor Loadings } \\
\text { (Child } \boldsymbol{n = 3 5 1 )}\end{array}$ \\
\hline Q3: Being in nature makes me very happy. & 0.905 & 0.872 & 0.816 \\
Q5: I find being in nature amazing. & 0.884 & 0.897 & 0.839 \\
Q1: I always find beauty in nature. & 0.877 & 0.814 & 0.783 \\
Q4: Spending time in nature is very important to me. & 0.876 & 0.867 & 0.796 \\
Q2: I always treat nature with respect. & 0.781 & 0.687 & 0.622 \\
Q6: I feel part of nature. & 0.767 & 0.807 & 0.699 \\
\hline
\end{tabular}

\subsection{Comparison Study}

Table 7 shows the relationships between the NCI and other measures taken from the online comparison study. Regarding concurrent validity, it can be seen that there are strong positive correlations between the NCI and existing nature connectedness measures, the INS and NR6. These three measures also relate well to Engagement with Nature's Beauty. Regarding the relationship to other affect related measures included in previous research, the INS and NCI correlate with a similar level with happiness and emotional regulation, whereas the NR6 did not.

Table 7. The relationships between the NCI and scales from the online comparison study (adults, $n=153)$.

\begin{tabular}{lcccccc}
\hline & NCI & NR6 & INS & EWNB & Happiness & DERS \\
\hline NCI & 1 & & & & & \\
NR6 & $0.672^{* *}$ & 1 & & & & \\
INS & $0.526^{* *}$ & $0.546^{* *}$ & 1 & & & \\
EWNB & $0.586^{* *}$ & $0.731^{* *}$ & $0.432^{* *}$ & 1 & 1 & 1 \\
Happiness & $0.308^{* *}$ & 0.156 & $0.318^{* *}$ & 0.117 & $-0.549^{* *}$ & 1 \\
DERS & $-0.220^{* *}$ & -0.098 & $-0.297^{* *}$ & 0.004 & & \\
\hline
\end{tabular}

Key: NCI = Nature Connection Index; NR6 = Nature Relatedness Scale; INS = Inclusion of Nature in Self; EWNB =

Engagement with Natural Beauty; DERS $=$ Difficulties in Emotion Regulation Scale. ${ }^{* *}=$ significant at $p<0.01$.

Finally, Table 8 includes the descriptive statistics from the various NCI data sources (e.g., MENE, online). These data show the impact of the weighting index, distribution characteristics, and impact of online collection. The similarity of the data helps confirm that the scale can be used face to face and online. Data from the evaluation of 30 Days Wild [10] is also included as it is the first use of the scale in an applied context, as one might expect this reveals that participants volunteering to take part in a large-scale nature-based campaign have higher levels of nature connectedness than the population mean. This helps demonstrate the utility of the measure. 
Table 8. Summary of all nature connectedness measures from both the MENE and online samples.

\begin{tabular}{|c|c|c|c|c|c|c|c|c|}
\hline & Mean & SD & Median & $\begin{array}{l}\text { Max } \\
\text { Score }\end{array}$ & $\begin{array}{l}\text { Mean \% } \\
\text { of Max }\end{array}$ & $\begin{array}{c}\text { Median \% } \\
\text { of Max }\end{array}$ & Skew & Kurtosis \\
\hline $\begin{array}{l}\text { MENE Data NCI raw } \\
n=3568\end{array}$ & 34.65 & 6.57 & 36 & 42 & 82.5 & 85.71 & -1.01 & 1.061 \\
\hline $\begin{array}{l}\text { MENE Data NCI Weighted } \\
n=3568\end{array}$ & 61.16 & 27.88 & 59 & 100 & 61.16 & 59 & -0.03 & -1.179 \\
\hline $\begin{array}{l}\text { MENE Child Data NCI raw } \\
n=351 \\
\text { MENE Child Data NCI }\end{array}$ & 33.59 & 6.58 & 35 & 42 & 79.98 & 83.33 & -1.000 & 0.721 \\
\hline $\begin{array}{l}\text { Weighted } \\
n=351\end{array}$ & 57.45 & 25.43 & 57 & 100 & 57.45 & 54 & -0.032 & -0.857 \\
\hline $\begin{array}{l}\text { Online data NCI raw } \\
n=553\end{array}$ & 34.21 & 6.93 & 36 & 42 & 81.45 & 85.71 & -0.938 & 0.471 \\
\hline $\begin{array}{l}\text { Online data NCI Weighted } \\
n=553 \\
30 \text { Days Wild data [41] }\end{array}$ & 60.27 & 28.5 & 59 & 100 & 60.72 & 59 & -0.044 & -1.222 \\
\hline $\begin{array}{l}\text { Weighted } \\
n=6179\end{array}$ & 79.27 & 22.8 & 84 & 100 & 79.27 & 84 & -1.141 & 0.597 \\
\hline
\end{tabular}

\subsection{NCI, Behavioral and Attitudinal Variables in Adults (MENE Survey)}

The responses from the NCI were compared to standard questions in the MENE. Responses to the question "I am concerned about damage to the natural environment" were explored with the mean NCI for each response presented in Table 9. This shows a greater NCI for the highest level of concern about damage to the natural environment.

Table 9. Mean NCI for Responses to "I am concerned about damage to the natural environment"

\begin{tabular}{lccc}
\hline & Mean & $N$ & SD \\
\hline Strongly agree & 75.62 & 1135 & 24.49 \\
Agree & 57.08 & 1953 & 25.99 \\
Neither agree nor disagree & 42.76 & 311 & 25.66 \\
Disagree & 44.04 & 145 & 28.47 \\
Strongly disagree & 51.33 & 24 & 37.89 \\
\hline
\end{tabular}

Further analyses were performed to measure how NCI differed between responses to several behavioral variables captured by MENE (Table 10). The ecological correlation between percentage of participation in the ten behaviors and NCI of those participating was $0.97(p<0.01)$ suggesting that the behaviors requiring greater commitment (resulting in less participation) are strongly associated with greater NCI. Differences between yes and no responses were all significant when allowing for multiple comparisons $(p<0.01)$.

Table 10. Mean NCI and participation in pro-environmental behaviors captured by MENE.

\begin{tabular}{|c|c|c|c|c|c|}
\hline \multirow[b]{2}{*}{ Behaviors } & \multicolumn{2}{|c|}{ Yes } & \multirow[b]{2}{*}{$\begin{array}{c}\% \\
\text { Yes }\end{array}$} & \multicolumn{2}{|c|}{ No } \\
\hline & NCI Mean & NCI SD & & NCI Mean & NCI SD \\
\hline None of these & 47.53 & 27.99 & 11.6 & 62.95 & 27.37 \\
\hline Usually recycle & 63.39 & 27.38 & 76.2 & 53.99 & 28.28 \\
\hline Walk or cycle instead of car & 66.27 & 26.02 & 46.0 & 56.80 & 28.67 \\
\hline Buy seasonal or locally grown food & 69.51 & 26.03 & 34.1 & 56.83 & 27.88 \\
\hline Usually buy eco-friendly products & 71.09 & 25.38 & 24.4 & 57.95 & 27.90 \\
\hline Encourage others to protect environment & 72.46 & 24.96 & 27.5 & 56.87 & 27.74 \\
\hline Signed a petition for conservation campaign & 73.42 & 24.08 & 8.9 & 59.96 & 27.94 \\
\hline Donate money to environmental or conservation organization & 74.11 & 26.07 & 8.7 & 59.93 & 27.74 \\
\hline Donate time to environmental or conservation organization & 74.56 & 24.98 & 3.5 & 60.68 & 27.86 \\
\hline Member of conservation organization & 76.12 & 22.66 & 7.0 & 60.04 & 27.92 \\
\hline Volunteer to help the environment & 76.23 & 24.49 & 4.8 & 60.39 & 27.83 \\
\hline
\end{tabular}




\subsection{Value-Action Gap}

Chi-square tests performed to examine those scoring 100 on the NCI and responses to the behaviors listed in Table 10, showed in increased likelihood of pro-environmental behavior for those with maximum scores. The tests were all significant $(p<0.01)$. However, a value-action gap can be observed in that whereas $19 \%$ of respondents scored the maximum NCI of $100 \%$ (see Figure 1), fewer than $5 \%$ of respondents volunteered or gave their own time to conservation and environmental causes (see Table 10). Finally, those with the maximum NCI score of one hundred $(n=683)$ were significantly happier, more satisfied with life, and less anxious, than those scoring below one hundred $(n=2885$; $p<0.01)$, see Table 11.

Table 11. Subjective well-being scores for those with a maximum vs below-maximum NCI scores.

\begin{tabular}{llccc}
\hline NCI Level & & Life Satisfaction & Happiness & Anxiety \\
\hline \multirow{3}{*}{$<100$} & Mean & 7.45 & 7.41 & 2.22 \\
& N & 2983 & 2983 & 2983 \\
& SD & 1.935 & 2.224 & 2.723 \\
\hline \multirow{3}{*}{100} & Mean & 7.87 & 8.06 & 1.94 \\
& N & 683 & 683 & 683 \\
& SD & 1.982 & 2.168 & 2.721 \\
\hline
\end{tabular}

\section{Discussion}

The results of the study confirmed the validity and reliability of the NCI as a measure for nature connectedness. The EFA on the different cohorts found that the items measure one factor and show high internal consistency. This demonstrates the reliability of the scale. Furthermore, the similar EFA results of all three cohorts ( 2 adult cohorts and children), as well as high correlations between other nature connectedness measures, supports the concurrent validity of the scale. Finally, the positive correlation between the $\mathrm{NCI}$ and the happiness measure is in line with existing research on the positive association between subjective well-being and nature connectedness [54].

As expected, the EFAs conducted in this study suggested that the NCI is composed of a single factor; labelled nature connectedness. Encouragingly, all six of the items of the NCI loaded strongly onto the factor $(>0.62)$, with these factor loadings comparable in both magnitude and order, with few exemptions, across samples. The lower figures related to children's data on the treating nature with respect item. In addition to this strong evidence, the identical factor solutions produced provides robust evidence for the reliability of scale. If data that is collected from different samples on different occasions produces identical factor solutions, the likelihood of those results being false is small [55].

The relationships between the NCI and other scales provides evidence of validity and wider insight. In terms of validity, the NCI correlates strongly with the existing short measure, the Nature Relatedness Scale (NR6) and to the single-item INS. This supports the validity of the scale as a measure for nature connectedness. More widely, the relationship to well-being shown by the correlations was slightly stronger for the NCI and INS, compared to the NR-6. The NCI also correlates well with the related EWNB measure, with a score between that of the NR6 and INS. Although the NR6 relates well to EWNB, it has a weak relationship with Difficulties in Emotional Regulation Scale, while the NCI and INS have stronger relationships. As an affect-based approach was taken to the development of the NCI this would be expected and indicates utility as a measure to evaluate an affective connection with nature. The relationship to affect regulation and beauty is important as both have been found to mediate the relationship between nature connectedness and well-being [20].

The repeated factor analysis results and comparison to existing measures support the reliability and validity of the NCI. However, the proportion of people who scored 100 on the NCI was a notable feature of the scale. The proportion of high scores raises concerns about the utility of the scale for detecting differences, during pre-post evaluations for example. However, the NCI has 
also been shown to successfully identify such changes and replicate findings found with existing measures of connectedness to nature [10]. Furthermore, rather than a distribution skewed and curtailed at the ceiling, a non-unimodal distribution can be observed with a peak in the frequency of scores around the mid-point, with a second peak of very high scores. This may in part be an artifact of designing a scale suitable for children as well as adults, although the child data also has a similar distribution. Non-unimodal distributions have been used to investigate subgroups within a construct [57], and bimodality can suggest latent groups [58]; however observed bimodality does not preclude a continuous dimension [59].

Given the robust sampling of the MENE survey the distribution demonstrates a genuine situation within the population and can provide useful insight. For example, combined with responses to the MENE questions related to attitudes and behaviors it highlights the value-action gap. Analysis has shown that there are significant differences in engagement with pro-environmental behaviors between participants scoring 100 and those scoring less than 100. These differences were also found for well-being (happiness, life satisfaction, anxiousness). The results suggest that the people scoring 100 do indeed have high levels of connectedness to nature, which shows in behavioral and well-being differences to people who have a level of nature connectedness below 100. However, many of those scoring highly were not engaging in pro-environmental behaviors. The importance of nature connectedness in ecological behaviors has also been found in previous research [8]. Detailed analysis of the relationship between behaviors and nature connectedness will be explored more fully in a follow-up paper.

Regarding demographics, the NCI showed utility as a population measure, revealing some differences by age, gender, and modest differences by socio-economic groups. However, these differences are small, which demonstrates a stable construct across the population, apart from during childhood where notable differences can be observed.

In sum, given the large sample based on robust national statistics protocols and strong single factor solution across samples, the results suggest that the weighted NCI can be recommended for use Internationally in English speaking populations for both children and adults. Although initial evidence suggests that nature connectedness is a construct stable across cultures [33], validation of translated scales is advisable and such work could seek to confirm the item weightings. The weighting, characteristics of the index and relationship to pro-environmental behaviors suggest the population mean is currently insufficient for a sustainable future and a score in the upper quartile, even of 100, can be targeted. Finally, there are also good indications that the NCI can identify changes in nature connectedness following interventions through baseline, post and follow-up measurement [10].

Although the number of children within the narrow age bands is relatively small on occasion, the size and suddenness of the drop in levels of nature connectedness from 10 to 15 years of age is notable. The larger sample in the wider age bands give confidence in a drop in nature connectedness through adolescence. Recent data using both the childhood CNI measure and NR6 has also identified at drop in nature connectedness at this point [60], which provides further confirmation of the validity of the scale. Similarly, qualitative research has identified a loss of interest in natural spaces at adolescence [61]. Although cross-sectional, rather than longitudinal, it seems likely that the profile represents developmental changes or situational factors, rather than transitory events affecting children born in and soon after 2005. Regarding developmental changes, adolescence is a time of the development of self-identity and the emotional regulation required for social relationships [62]. The self is a key perspective in nature connectedness [14] and higher nature connectedness is related to fewer difficulties in emotional regulation [20]. As children change their use and requirements of nature and natural spaces will change. For example, natural environments such as woodlands can provide opportunities for developing a sense of identity, but this is poorly understood and tolerated by landowners and managers [61]. Regarding situational factors, adolescents within the UK sample are also subject to external changes, such as the move from a primary to secondary school environment. 
Considering the psychological factors further, identity formation theory [63] suggests that at this developmental stage, achieving a clear and defined identity is a crucial process to becoming a productive adult. The adoption of specific values and goals may not prioritize nature, particularly in a technology focused generation. The theorized identity crisis that ensues sees childhood characteristics merge with emerging adolescent traits, and is theorized to consist of a series of stages alongside coping with, for example, physical growth, group acceptance, love, and career choices. It may be that during this time, nature and one's connection with nature, may lose relevance and importance. Thus, a child transitioning into adolescence may temporarily discount the importance of nature until a stable identity is formed.

Further research is required to identify the factors found to be associated with the adolescent disconnect. This will inform efforts to prevent the decline or facilitate re-connection. Such efforts to improve nature connectedness can be based on approaches which include contact, emotions, beauty, meaning and compassion [21]. For example, it has been found nature connectedness can be increased by including affective elements in outdoor education programs [64], whereas a more traditional outdoors adventure program did not increase nature connectedness [65].

In conclusion, this study found NCI to be a reliable and valid scale that offers a short, simple alternative to other measures of nature connectedness, particularly for populations including both children and adults, measured face to face or online. The utility of the NCI for exploring key issues for a sustainable future is also supported by the associations with various pro-environmental behaviors. Finally, wider research has shown the NCI can detect increases in nature connectedness during evaluation [10]. Importantly, the NCI also provides a tool that can be used to reveal changes in nature connectedness across the lifespan. With the critical global issues of climate change and biodiversity loss symptomatic of human disconnection with nature, there is a growing interest in understanding and improving people's connection to nature. The NCI provides a population measure that can be used internationally to help understand and track improvement in nature connectedness to inform policy in this area.

Author Contributions: M.R., J.H., A.H., R.B. worked on the initial design and specification of the scale. D.F., M.R., M.W., D.P. contributed to data preparation and analysis. T.C. designed and collected online data. M.R., D.F., L.B., A.H., M.W. contributed to paper writing and review.

Funding: Funding was provided by the following project partners: Natural England, Historic England, University of Derby, National Trust, Royal Society for the Protection of Birds and The Wildlife Trusts.

Conflicts of Interest: The authors declare no conflicts of interest.

\section{References}

1. Ives, C.D.; Giusti, M.; Fischer, J.; Abson, D.J.; Klaniecki, K.; Dorninger, C.; Raymond, C.M. Human-Nature connection: A multidisciplinary review. Curr. Opin. Environ. Sustain. 2017, 26, 106-113. [CrossRef]

2. DEFRA. A Green Future: Our 25 Year Plan to Improve the Environment; DEFRA: London, UK, 2018.

3. Frankish, H.; Boyce, N.; Horton, R. Mental health for all: A global goal. Lancet 2018, 392, 1493-1495. [CrossRef]

4. Ceballos, G.; Ehrlich, P.R.; Dirzo, R. Biological annihilation via the ongoing sixth mass extinction signaled by vertebrate population losses and declines. Proc. Natl. Acad. Sci. USA 2017, 114, E6089-E6096. [CrossRef] [PubMed]

5. Richardson, M.; Maspero, M.; Golightly, D.; Sheffield, D.; Staples, V.; Lumber, R. Nature: A new paradigm for Well-Being and ergonomics. Ergonomics 2017, 60, 292-305. [CrossRef] [PubMed]

6. Pritchard, A.; Richardson, M.; Sheffield, D.; McEwan, K. The Relationship Between Nature Connectedness and Eudaimonic Well-Being: A Meta-Analysis. J. Happiness Stud. 2019. [CrossRef]

7. Abrahamse, W.; Steg, L.; Vlek, C.; Rothengatter, T. A review of intervention studies aimed at household energy conservation. J. Environ. Psychol. 2005, 25, 273-291. [CrossRef] 
8. Otto, S.; Pensini, P. Nature-based environmental education of children: Environmental knowledge and connectedness to nature, together, are related to ecological behavior. Glob. Environ. Chang. 2017, 47, 88-94. [CrossRef]

9. Otto, S.; Neaman, A.; Richards, B.; Marió, A. Explaining the ambiguous relations between income, environmental knowledge, and environmentally significant behavior. Soc. Natl. Resour. 2016, 295, 628-632. [CrossRef]

10. Richardson, M.; McEwan, K.; Garip, G. 30 Days Wild: Who benefits most? J. Public Ment. Health 2018, 17, 95-104. [CrossRef]

11. Tam, K.P. Concepts and measures related to connection to nature: Similarities and differences. J. Environ. Psychol. 2013, 34, 64-78. [CrossRef]

12. Mayer, F.S.; Frantz, C.M. The connectedness to nature scale: A measure of individuals' feeling in community with nature. J. Environ. Psychol. 2004, 24, 503-515. [CrossRef]

13. Zelenski, J.M.; Nisbet, E.K. Happiness and Feeling Connected the Distinct Role of Nature Relatedness. Environ. Behav. 2014, 46, 3-23. [CrossRef]

14. Schultz, P.W. Inclusion with Nature: The Psychology of Human-Nature Relations. In Psychology of Sustainable Development; Schmuck, P., Schultz, P.W., Eds.; Springer: Boston, MA, USA, 2002; pp. 61-78.

15. Cheng, J.; Monroe, M. Connection to nature: Children's affective attitude toward nature. Environ. Behav. 2012, 44, 31-49. [CrossRef]

16. Perrin, J.L.; Benassi, V.A. The connectedness to nature scale: A measure of emotional connection to nature? J. Environ. Psychol. 2009, 29, 434-440. [CrossRef]

17. Louv, R. Last Child in the Woods: Saving our Children from Nature-Deficit Disorder; Algonquin Books: Chapel Hill, NC, USA, 2008.

18. Hughes, J.; Richardson, M.; Lumber, R. Evaluating connection to nature and the relationship with conservation behavior in children. J. Nat. Conserv. 2018, 45, 11-19. [CrossRef]

19. Hinds, J.; Sparks, P. Engaging with the natural environment: The role of affective connection and identity. J. Environ. Psychol. 2008, 28, 109-120. [CrossRef]

20. Richardson, M.; McEwan, K. 30 Days Wild and the Relationships Between Engagement with Nature's Beauty, Nature Connectedness and Well-Being. Front. Psychol. 2018, 9. [CrossRef] [PubMed]

21. Lumber, R.; Richardson, M.; Sheffield, D. Beyond knowing nature: Contact, emotion, compassion, meaning, and beauty are pathways to nature connection. PLoS ONE 2017, 12, e0177186. [CrossRef] [PubMed]

22. Kellert, S.H. The Biological Basis for Human Values of Nature. In The Biophilia Hypothesis; Kellert, S.H., Wilson, E.O., Eds.; Island: Washington, DC, USA, 1993.

23. Bragg, R.; Wood, C.; Barton, J.; Pretty, J. Measuring Connection to Nature in Children Aged 8-12: A Robust Methodology for the RSPB; RSPB: Sandy, UK, 2013.

24. Kals, E.; Schumacher, D.; Montada, L. Emotional affinity toward nature as a motivational basis to protect nature. Environ. Behav. 1999, 31, 178-202. [CrossRef]

25. Howell, A.J.; Dopko, R.L.; Passmore, H.A.; Buro, K. Nature connectedness: Associations with well-being and mindfulness. Personal. Ind. Diff. 2011, 51, 166-171. [CrossRef]

26. Hinds, J. Exploring the psychological rewards of a wilderness experience: An interpretive phenomenological analysis. Hum. Psychol. 2011, 39, 189-205. [CrossRef]

27. Hinds, J.; Sparks, P. The affective quality of human-natural environment relationships. Evolut. Psychol. 2011, 9, 451-469. [CrossRef]

28. Richardson, M.; Hallam, J.; Lumber, R. One thousand good things in nature: The aspects of nature that lead to increased nature connectedness. Environ. Values 2015, 24, 603-619. [CrossRef]

29. Richardson, M.; Hallam, J. Exploring the psychological rewards of a familiar semirural landscape: Connecting to local nature through a mindful approach. Hum. Psychol. 2013, 41, 35-53. [CrossRef]

30. White, P.R. Enhancing the experience of connection with nature: Participants' responses to the MAPIN strategy. Ecopsychology 2012, 4, 345-354. [CrossRef]

31. Kaplan, S. Aesthetics, affect, and cognition: Environmental preferences from an evolutionary perspective. Environ. Behav. 1987, 19, 3-32. [CrossRef]

32. Zhang, J.W.; Howell, R.T.; Iyer, R. Engagement with natural beauty moderates the positive relation between connectedness with nature and psychological well-being. J. Environ. Psychol. 2014, 38, 55-63. [CrossRef] 
33. Capaldi, C.A.; Passmore, H.A.; Ishii, R.; Chistopolskaya, K.A.; Vowinckel, J.; Nikolaev, E.L.; Semikin, G.I. Engaging with natural beauty may be related to well-being because it connects people to nature: Evidence from three cultures. Ecopsychology 2017, 9, 199-211. [CrossRef]

34. Beery, T.H.; Wolf-Watz, D. Nature to Place: Rethinking the Environmental. J. Environ. Psychol. 2014, 40, 198-205. [CrossRef]

35. Nisbet, E.K.; Zelenski, J.M. Underestimating nearby nature affective forecasting errors obscure the happy path to sustainability. Psychol. Sci. 2011, 22, 1101-1106. [CrossRef] [PubMed]

36. Nisbet, E.K.; Zelenski, J.M.; Murphy, S.A. Happiness is in our nature: Exploring nature relatedness as a contributor to subjective well-being. J. Happiness Stud. 2011, 122, 303-322. [CrossRef]

37. Bragg, R.; Wood, C.; Barton, J. Ecominds: Effects on Mental Wellbeing; Mind: London, UK, 2013.

38. Clayton, S. Environmental Identity: A Conceptual and an Operational Definition. In Identity and the Natural Environment; Clayton, S., Opotow, S., Eds.; MIT Press: Cambridge, MA, USA, 2003; pp. 45-65.

39. Flynn, R.; Bellaby, P.; Ricci, M. The 'Value-Action Gap'in public attitudes towards sustainable energy: The case of hydrogen energy. Sociol. Rev. 2009, 57, 159-180. [CrossRef]

40. Davis, J.L.; Le, B.; Coy, A.E. Building a model of commitment to the natural environment to predict ecological behavior and willingness to sacrifice. J. Environ. Psychol. 2011, 31, 257-265. [CrossRef]

41. Kahn, P.H. Developmental psychology and the Biophilia hypothesis: Children's affiliation with nature. Dev. Rev. 1997, 17, 1-61. [CrossRef]

42. Nisbet, E.K.; Zelenski, J.M.; Murphy, S.A. The nature relatedness scale: Linking individuals' connection with nature to environmental concern and behavior. Environ. Behav. 2009, 41, 715-740. [CrossRef]

43. Davis, J.L.; Green, J.D.; Reed, A. Interdependence with the environment: Commitment, interconnectedness, and environmental behavior. J. Environ. Psychol. 2009, 29, 173-180. [CrossRef]

44. Schultz, P.W. The structure of environmental concern: Concern for self, other people, and the biosphere. J. Environ. Psychol. 2001, 21, 327-339. [CrossRef]

45. Hunt, A.; Stewart, D.; Richardson, M.; Hinds, J.; Bragg, R.; White, M.; Burt, J. Monitor of Engagement with the Natural Environment: Developing a Method to Measure Nature Connection Across the English Population (Adults and Children); Natural England Commissioned Reports Number 233; Natural England publications: York, UK, 2017.

46. Emerson, J.D. Mathematical Aspects of Transformation. In Understanding Robust and Exploratory Data Analysis; Hoaglin, D.C., Mosteller, F., Tukey, J.W., Eds.; John Wiley: New York, NY, USA, 1983.

47. Burgess, J.; Harrison, C.M.; Filius, P. Environmental communication and the cultural politics of environmental citizenship. Environ. Plan. A 1998, 30, 1445-1460. [CrossRef]

48. Frick, J.; Kaiser, F.G.; Wilson, M. Environmental knowledge and conservation behavior: Exploring prevalence and structure in a representative sample. Personal. Ind. Diff. 2004, 37, 1597-1613. [CrossRef]

49. Nisbet, E.K.; Zelenski, J.M. The NR-6: A new brief measure of nature relatedness. Front. Psychol. $2013,4,813$. [CrossRef] [PubMed]

50. Diessner, R.; Solom, R.D.; Frost, N.K.; Parsons, L.; Davidson, J. Engagement with beauty: Appreciating natural, artistic, and moral beauty. J. Psychol. 2008, 142, 303-332. [CrossRef] [PubMed]

51. Bjureberg, J.; Ljótsson, B.; Tull, M.T.; Hedman, E.; Sahlin, H.; Lundh, L.G.; Gratz, K.L. Development and validation of a brief version of the difficulties in emotion regulation scale: The DERS-16. J. Psychopathol. Behav. Assess. 2016, 38, 284-296. [CrossRef] [PubMed]

52. Berna, G.; Ott, L.; Nandrino, J.L. Effects of emotion regulation difficulties on the tonic and phasic cardiac autonomic response. PLoS ONE 2014, 9, e102971. [CrossRef] [PubMed]

53. Abdel-Khalek, A.M. Measuring happiness with a single-item scale. Soc. Behav. Personal. Int. J. 2006, 34, 139-150. [CrossRef]

54. Capaldi, C.A.; Dopko, R.L.; Zelenski, J.M. The relationship between nature connectedness and happiness: A meta-analysis. Front. Psychol. 2014, 5, 976. [CrossRef] [PubMed]

55. DeVellis, R.F. Scale Development: Theory and Applications, 3rd ed.; Sage Publications: Thousand Oaks, CA, USA, 2012.

56. Stevens, J.P. Applied Multivariate Statistics for the Social Sciences, 2nd ed.; Erlbaum: Hillsdale, NJ, USA, 1992.

57. Munson, J.; Dawson, G.; Sterling, L.; Beauchaine, T.; Zhou, A.; Koehler, E.; Abbott, R. Evidence for latent classes of IQ in young children with autism spectrum disorder. Am. J. Ment. Retard. 2008, 113, 439-452. [CrossRef] [PubMed] 
58. Meehl, P.E. Bootstraps taxometrics: Solving the classification problem in psychopathology. Am. Psychol. 1995, 50, 266-275. [CrossRef] [PubMed]

59. Grayson, D.A. Can categorical and dimensional views of psychiatric illness be distinguished? Br. J. Psychiatry 1987, 151, 355-361. [CrossRef] [PubMed]

60. Hughes, J.; Rogerson, M.; Barton, J.; Bragg, R. Age and connection to nature: When is engagement critical? Front. Ecol. Environ. 2019. [CrossRef]

61. Bell, S.; Thompson, C.W.; Travlou, P. Contested views of freedom and control: Children, teenagers and urban fringe woodlands in Central Scotland. Urban For. Urban Green. 2003, 2, 87-100. [CrossRef]

62. National Research Council. The Science of Adolescent Risk-Taking: Workshop Report; National Academies Press: Washington, DC, USA, 2011.

63. Erikson, E. Youth: Identity and Crisis; W. W. Norton: New York, NY, USA, 1968.

64. Braun, T.; Dierkes, P. Connecting students to nature-How intensity of nature experience and student age influence the success of outdoor education programs. Environ. Educ. Res. 2017, 23, 937-949. [CrossRef]

65. Williams, I.R.; Rose, L.M.; Raniti, M.B.; Waloszek, J.; Dudgeon, P.; Olsson, C.A.; Allen, N.B. The impact of an outdoor adventure program on positive adolescent development: A controlled crossover trial. J. Outdoor Environ. Educ. 2018, 21, 207-236. [CrossRef]

(C) 2019 by the authors. Licensee MDPI, Basel, Switzerland. This article is an open access article distributed under the terms and conditions of the Creative Commons Attribution (CC BY) license (http://creativecommons.org/licenses/by/4.0/). 